\title{
In reply: Physical distancing or social distancing: that is the question
}

\author{
Meghan Prin, MD, MS • Karsten Bartels, MD, PhD
}

Received: 30 April 2020/Revised: 30 April 2020/Accepted: 1 May 2020/Published online: 11 May 2020

(c) Canadian Anesthesiologists' Society 2020

To the Editor,

We appreciate the interest of Aminnejad and Alikhani ${ }^{1}$ in our recent publication on social distancing practices for the operating room, ${ }^{2}$ and are grateful for the opportunity to respond. We wholeheartedly agree with the importance of addressing mental health concerns amongst the many challenges of the current pandemic. This is not a new concern by any means. For example, during the 1918 Spanish flu pandemic, the Health Commissioner of New York City declared, “...my aim was to prevent panic, hysteria, mental disturbance, and thus to protect the public from the condition of mind that in itself predisposes to physical ills." 3 In the current coronavirus disease pandemic, effects on population mental health may be significant. Among other factors, isolation, as well as feelings of entrapment, loneliness, and bereavement can contribute to an increased suicide risk. Interventions emphasizing community support, as well as friends and family contact, are indeed recommended. ${ }^{4}$

Social distancing is increasing the physical distance between people to prevent the spread of disease. We wrote our paper to emphasize that this practice must be applied in the professional arena, even in high-stress work environments in which close physical contact is

\footnotetext{
M. Prin, MD, MS

Department of Anesthesiology, School of Medicine, University of Colorado, Aurora, CO, USA

K. Bartels, MD, PhD ( $\square)$

Department of Anesthesiology, School of Medicine, University of Colorado, Aurora, CO, USA

e-mail: karsten.bartels@ucdenver.edu
}

Department of Surgery, School of Medicine, University of Colorado, Aurora, CO, USA historically the norm (e.g., the operating room). Nevertheless, we agree that social distance should not be construed to imply social isolation. We described the importance of effective communication styles that may enhance not only productivity but also human interaction, and encourage a nuanced approach to social distancing in all settings so that we feel connected and supported in all the communities in which we live and work.

Disclosures None.

Funding statement None.

Editorial responsibility This submission was handled by Dr. Hilary P. Grocott, Editor-in-Chief, Canadian Journal of Anesthesia.

\section{References}

1. Aminnejad R, Alikhani R. Physical distancing or social distancing: that is the question. Can J Anesth. 2020. DOI: https://doi.org/10. 1007/s12630-020-01697-2.

2. Prin M, Bartels K. Social distancing: implications for the operating room in the face of COVID-19. Can J Anesth. 2020. DOI: https:// doi.org/10.1007/s12630-020-01651-2.

3. Tomes N. "Destroyer and teacher": managing the masses during the 1918-1919 influenza pandemic. Public Health Rep. 2010;125(Suppl 3):48-62.

4. Gunnell D, Appleby L, Arensman E, et al. Suicide risk and prevention during the COVID-19 pandemic. Lancet Psychiatry. 2020. DOI: https://doi.org/10.1016/S2215-0366(20)30171-1.

Publisher's Note Springer Nature remains neutral with regard to jurisdictional claims in published maps and institutional affiliations. 